\title{
Novel syndromes of hypoinsulinaemic, hypoketotic hypoglycaemia
}

Sarah M Leiter (1), Marina Minic (1), Victoria Parker (1), Julie Harris (1), Julian Hamilton-Shield (2), Rachel Williams (3), Khalid Hussain (4), Robert Semple (1)

\section{Introduction}

Hypoglycaemia in infancy is commonly caused by hyperinsulinism and is characterised by low ketones, low free fatty acids and low branched-chain amino acids during hypoglycaemia, and a high glucose infusion rate to maintain euglycaemia.

Hypoketotic hypoglycaemia in the absence of detectible serum insulin can be caused by an activating mutation in serine-threonine kinase AKT2 (PKB $\beta$ ) leading to hyperactivation of the AKT2-dependent arm of the insulin signalling cascade $(1,2)$. These patients have a lower requirement for glucose and show left-sided hemihypertrophy.

Here we present a series of five further patients with hypoketotic hypoglycaemia and suppressed insulin but no activating mutation in AKT2, and outline our approach to identifying the underlying genetic and cellular causes.

\section{Patient 1 case history}

\section{Patient Group}

born at 35 weeks of gestation. Birth weight $3.05 \mathrm{~kg}(+0.98 \mathrm{SD})$, length $48 \mathrm{~cm}(+0.05 \mathrm{SD})$, and head circumference $35 \mathrm{~cm}(+1.10 \mathrm{SD})$

non-consanguineous German parents

bilateral renal masses noted during gestation (diagnosed as bilateral cystic nephropathy)

Hypoglycaemica $(0.4 \mathrm{mmol} / \mathrm{l})$ noted at 2 days (Table 1$)$

no urinary ketones during hypoglycaemia

preserved mobilisable glucagon stores as evidenced by glucagon response

short synacthen test confirmed normal adrenal function; steroids ineffective

required parenteral glucose $(10-19 \mathrm{mg} / \mathrm{kg} /$ day $)$ to maintain euglycaemia

Left adrenal mass noted post-natally on ultrasound

surgical removal did not improve hypoglycaemia

histology revealed a high-grade adrena; tumour with some normal parenchyma

no evidence increased "big" IGF in tumour or blood

Left-sided hemihypertrophy was noted at age 2 and an MRI confirmed overgrowth of left-sided abdominal organs.

At 14 years old she had a fasting tolerance of around 5 hours and did not show any signs of developmental delay. Euglycaemia is currently maintained through frequent meals.

\begin{tabular}{|c|c|c|}
\hline & Patient 1 & Reference range in Euglycaemia \\
\hline Blood glucose (mmol/l) & 1.4 & Fasting: 3.5-5.9 \\
\hline Insulin (pmol/l) & $<10$ & $0-60$ \\
\hline Glucagon (ng/l) & 379 & $50-200$ \\
\hline Cortisol (nmol/l) & 552 & $>550$ \\
\hline$\beta \mathrm{OHB}(\mathrm{mmol} / \mathrm{l})$ & 0.0 & $<0.6$ \\
\hline Free fatty acids (mmol/l) & 0.37 & $<0.72$ \\
\hline Valine $(\mu \mathrm{mol} / \mathrm{l})$ & 98 & $139-474$ \\
\hline Leucine ( $(\mu \mathrm{mol} / \mathrm{l})$ & 39 & $85-169$ \\
\hline Isoleucine $(\mu \mathrm{mol} / \mathrm{l})$ & 15 & $31-105$ \\
\hline Adrenaline (ng/l) & 100 & $<140$ \\
\hline Lactate $(\mathrm{mmol} / \mathrm{I})$ & 0.61 & $0.5-2.2$ \\
\hline ACTH $(\mathrm{pmol} / \mathrm{l})$ & 5.72 & $2.2-13.3$ \\
\hline $\mathrm{pH}$ & 7.38 & 7.35-7.45 \\
\hline $\mathrm{HCO}_{3}^{-}(\mathrm{mEq} / \mathrm{l})$ & 22 & $20-29$ \\
\hline Ketouria, organic aciduria & negative & \\
\hline
\end{tabular}

Table 1 - summary of biochemical tests confirming hypoketotic, hypoglycaemia

Table 1 - summary of biochemical tests confirming hypote

\section{Further patients}

In addition to patient 1 , four further patients have been identified with hypoketotic,

hypoinsulinaemic hypoglycaemia. These show a variety of additional features. (Table 2 )

\begin{tabular}{|c|c|c|c|c|c|}
\hline ID & $\begin{array}{c}\text { Fasting } \\
\text { hypoglycaemia }\end{array}$ & $\begin{array}{l}\text { Insulin during } \\
\text { hypoglycamia }\end{array}$ & Low ketones & Overgrwth & Other features \\
\hline $\mathrm{P} 1$ & Yes & Undetectable & Yes & Left-sided & $\begin{array}{l}\text { bilateral cystic nephrophathy, adrenal } \\
\text { tumour }\end{array}$ \\
\hline P2 & Yes & Undetectable & Yes & none & none \\
\hline P3 & Yes & Undetectable & Yes & obesity & Obstructive sleep apnea, epilepsy \\
\hline P4 & Yes & Undetectable & Yes & Right-sided & $\begin{array}{l}\text { Jejunal atresia, liver disease associated } \\
\text { with parenteral feeding }\end{array}$ \\
\hline P5 & yes & Undetectable & Yes & $\begin{array}{l}\text { Dysmorphic } \\
\text { features }\end{array}$ & $\begin{array}{l}\text { Muscle hypotonia, } \\
\text { Hepatic fibrosis, } \\
\text { Arnold-Chiari malformation }\end{array}$ \\
\hline
\end{tabular}

Table 2 - overview over biochemical ov

absence of detectible serum insulin.

\section{Acknowledgments and references}

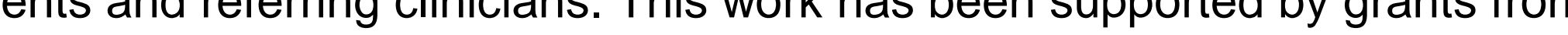
the Rosetrees Trust, Wellcome Trust, Medical Research Council and National Institute of Health Research and Human Hypoglycemia Science 2011:334(October):2011 2) Arya VB, Flanagan SE, Schober E, Rami-Merhar B, Ellard S, Hussain K. Activating AKT2 Mutation: Hypoinsulinemic Hypoketotic Hypoglycemia. J Clin Endocrinol Metab. 2014 Feb;99(2):391-4 1: Institute of Metabolic Science, University of Cambridge, Cambridge 2. Bistol Royal Hospla Scr Chidren, Bistol 3: Iestint sml45@medschl.cam.ac.uk

\section{Excluding AKT2 mutations and hyperactivation}

of the patient

Primary dermal fibroblasts are available for patients 1 and 3. ELISA and a quantified sandwiched immunoassay did not show basal hyperphosphorlyation of AKT2 or downstream target proteins. (Fig 1 )

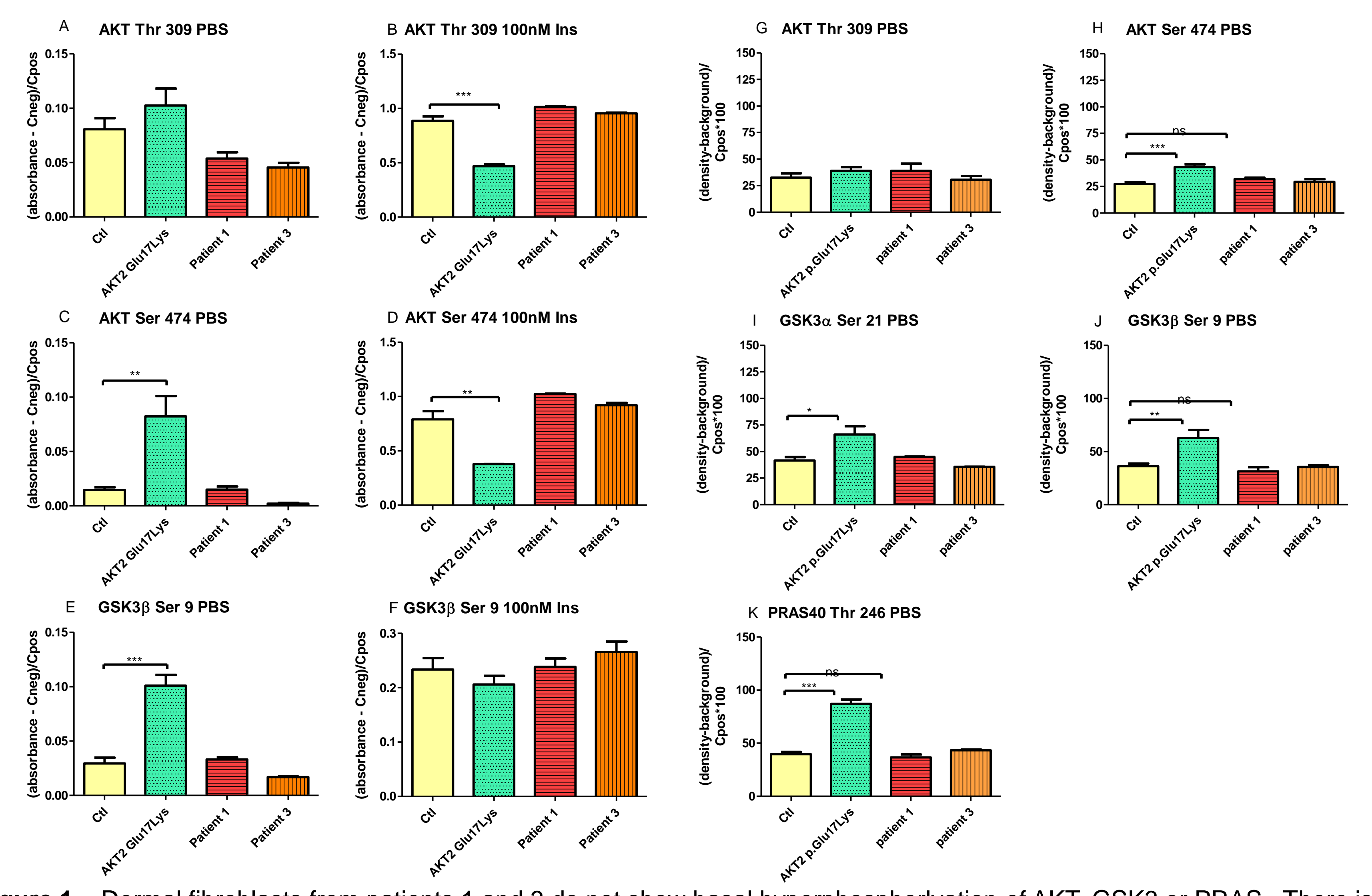

Figure 1 - Dermal fibroblasts from patients 1 and 3 do not show basal hyperphosphorlyation of AKT, GSK3 or PRAS. There is no *: $P \leq 0.05 ; * *: P \leq 0.01 ; * * *: P \leq 0.001$

\section{Analytic approach for novel syndromes}

Further investigation is focused on identifying both the genetic and cellular mechanisms underlying these syndromes (Fig. 2). FOXO1 is a key transcriptional regulator in hepatic gluconeogenesis which is translocated into the nucleus during the fasted state. Permanent nuclear exclusion has been demonstrated in cells from patients with the AKT2 p.Glu17Lys mutation.

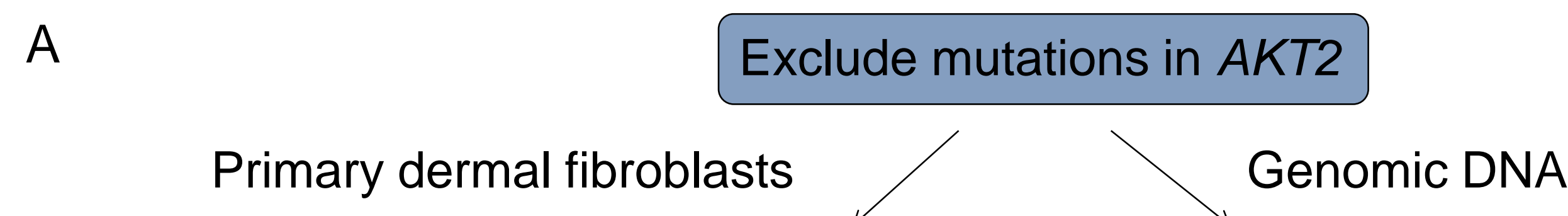

Assess AKT2 and downstream target phosphorylation during serum starvation

Assess FOXO1 localisation in cells using an inducible lentiviral GFPFOXO1 construct
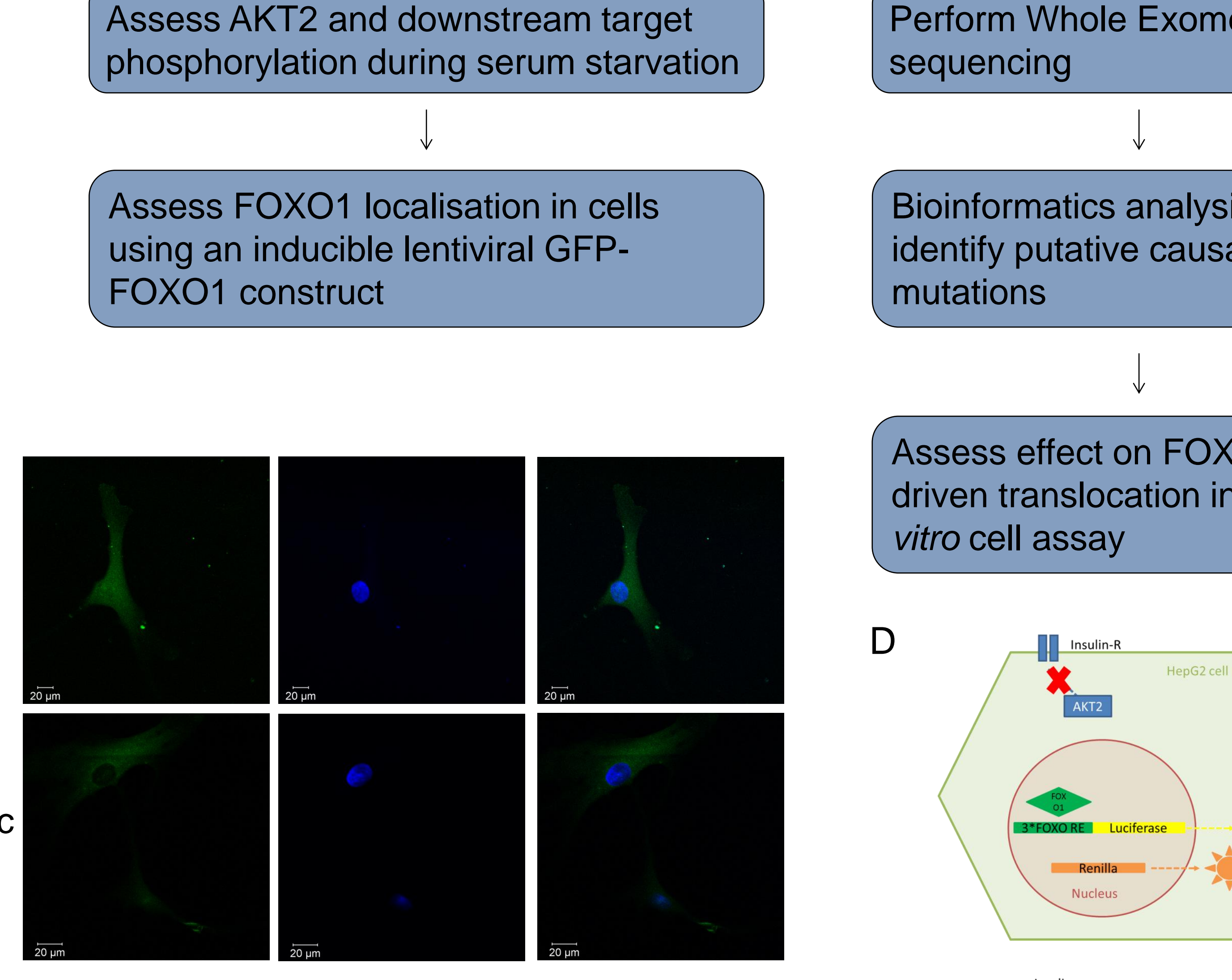

sequencing
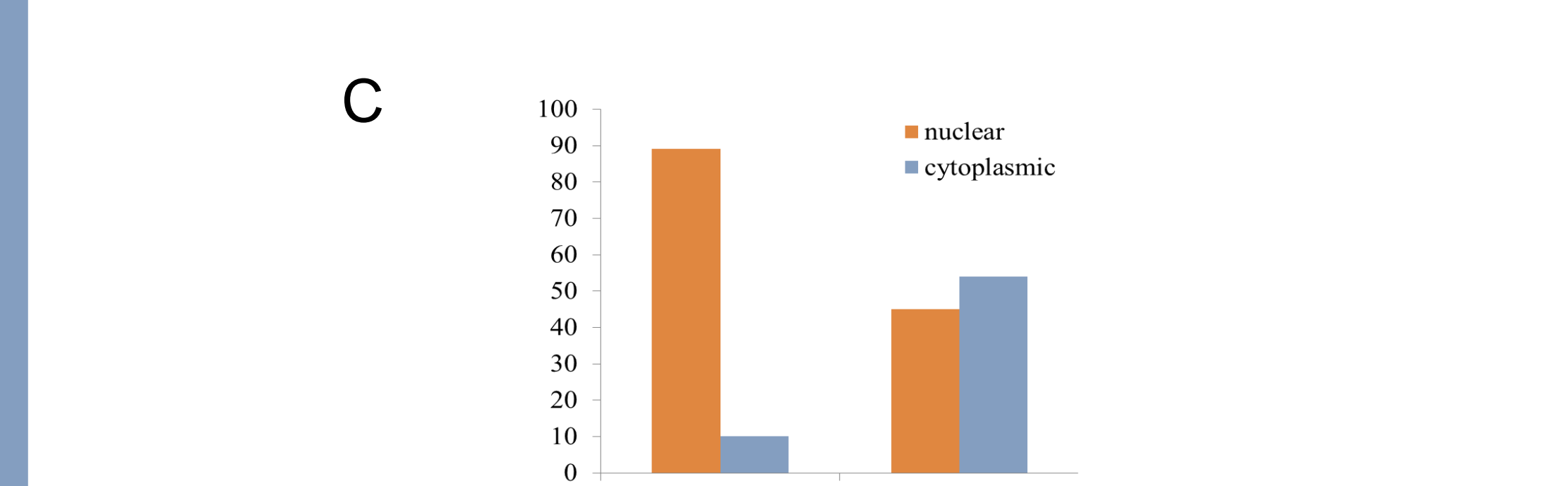

\section{Bioinformatics analysis to}

identify putative causative mutations$$
\text { nuc }
$$

cytoplas

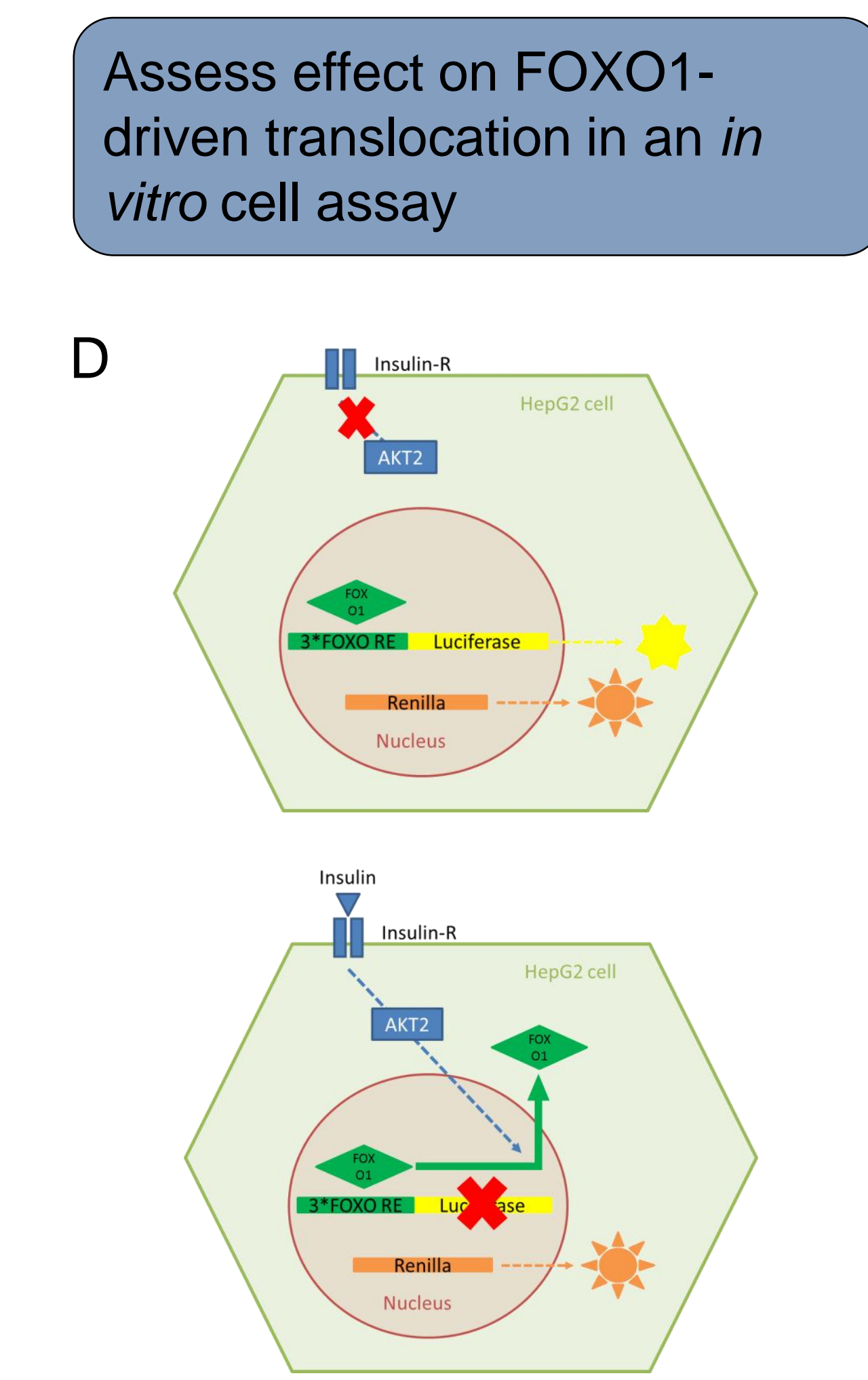

Figure 2 - Overview of approach taken to investigate these novel syndromes of hypoglycaem
A) Schematic showing two-part approach with primary cell investigation and genetics

Examples of fibroblasts infected with a GFP-FOXO1 lentivirus in the serum starved state

Dildation of lentinal vector hrough blinded sconng or 1

\section{Conclusions}

We present a group of five patients with a novel syndrome of hypoinsulinaemic, hypoketotic hypoglycaemia in the absence of a mutation in AKT2. The patients represent a biochemica phenocopy of the previously reported AKT2 p.Glu17Lys patients but lack basal hyperphosphorlyation of AKT2 and downstream kinases. Furthermore, the patients presented have a varied group of additional clinical feature including asymmetric overgrowth, adrenal tumors, polycystic kidneys, jejunal atresia, muslce hypotonia and hepatic fibrosis. Further investigations are underway to determine the genetic causes and cellular mechanisms. 